\title{
Comprehensive risk management for the prevention of cerebro- cardiovascular diseases in Japan
}

\author{
Joint Committee for Comprehensive Risk Management Chart for the Prevention of Cerebro- Cardiovascular \\ Diseases
}

Hypertension Research (2017) 40, 847-855; doi:10.1038/hr.2016.155; published online 13 July 2017

\section{INTRODUCTION}

The leading cause of mortality in Japan is cancer. However, when cardiovascular disease, the second leading cause of mortality, and cerebrovascular disease, the fourth most common cause, are combined as vascular disease, they account for almost as many deaths as cancer. Thus, preventions of cancer and vascular disease are extremely important health-care priorities in Japan. Cerebrovascular disease and cerebral hemorrhage in particular became overwhelmingly widespread in Japan in the 1960s. Guidance for improving lifestyle habits, such as sodium intake restriction, was successful in markedly reducing blood pressure and mortality rates, a proud time in history for preventive medicine. However, in recent years, despite decreases in the main coronary risk factors, hypertension incidence and smoking rates, the mortality rate for heart disease continues to rise. Furthermore, the mortality rate for cerebral infarction has not decreased and in fact has surpassed that of cerebral hemorrhage to exhibit a Western disease pattern.

The Hisayama study in Japan, an ongoing epidemiological research, also suggests that obesity, diabetes, and dyslipidemia now contribute more to cerebrovascular disease risk compared to past two decades. Accordingly, it is well recognized that in addition to blood pressure, the management of obesity, diabetes, and dyslipidemia, as well as chronic kidney disease (CKD), is pivotal for the prevention of cerebrocardiovascular diseases in Japan. Thus, methods of treatment and treatment guidelines are frequently updated for these diseases and physician specialists are well informed about them. However, some inconsistencies in the expressions used in these guidelines have been reported by general physicians.

There has been a growing momentum for mainly academic societies to engage in scientific research on such risk factors to develop comprehensive cerebro- cardiovascular disease management guidelines. Therefore, 11 societies including the Japanese Society for Internal Medicine agreed to participate in creating a 'Comprehensive Risk Management for the Prevention of Cerebro- Cardiovascular Diseases in Japan.' The Japan Medical Association and the Japanese Association of Medical Sciences, which approved cooperative work, also participated in this project, thereby enabling the creation of this practical management chart for general practitioners. Although the basic aim was to improve risk factors (obesity, blood pressure, blood glucose, serum lipids, kidney function, etc.) by comprehensive management of lifestyle habits as the basic concept is indicated in Figure 1, the importance of comprehensive management, including drug intervention, is emphasized in the case of multiple risk factors involved in each disease. Physicians must also keep in mind that in cases with genetic factors or in secondary disease groups, specific pharmacotherapy for the underlying disease is necessary.

It is most anticipated that this management chart will be utilized in medical settings throughout Japan and that comprehensive management of the diverse range of risk factors observed in individual patients will improve the prevention of cerebro- cardiovascular diseases, thereby leading to a healthier society.

Japan has one of the highest overall life expectancies and thus physicians must recognize that cerebro- cardiovascular diseases are more likely to occur in elderly patients. Of course, management must also take into account functional declines specific to the elderly (decreased renal function and muscle weakness in particular), but careful management should also be implemented due to the greater risks of cerebro- cardiovascular diseases in elderly individuals. We would like to introduce the comprehensive risk management chart for prevention of cerebro- cardiovascular diseases.

\footnotetext{
This is the English version of 'Comprehensive risk management for the prevention of cerebro- cardiovascular diseases in Japan', published in Japanese in April 2015. This article, copublished in the Journal of Epidemiology, is published on behalf of the Japan Epidemiological Association, Hypertension Research on behalf of the Japanese Society of Hypertension, Circulation Journal on behalf of the Japanese Circulation Society, Clinical and Experimental Nephrology on behalf of Japanese Society of Nephrology, The Journal of Physical Fitness and Sports Medicine on behalf of the Japanese Society of Physical Fitness and Sports Medicine, Diabetology International on behalf of the Japan Diabetes Society, Journal of Atherosclerosis and Thrombosis on behalf ofthe Japan Atherosclerosis Society, Journal of Japan Society for the Study of Obesity on behalf of the Japan Society for the Study of Obesity, and Geriatrics \& Gerontology International on behalf of the Japan Geriatrics Society.

The committee consisted of representatives from the following organizations: the Japan Epidemiological Association, the Japanese Society of Hypertension, the Japanese Circulation Society, Japanese Society of Nephrology, the Japanese Society of Physical Fitness and Sports Medicine, the Japan Diabetes Society, the Japan Atherosclerosis Society, the Japan Society for the Study of Obesity, and the Japan Geriatrics Society.

Correspondence: Joint Committee for Comprehensive Risk Management Chart for the Prevention of Cerebro- Cardiovascular Diseases, Nichinai-kaikan B1, 3-28-8 Hongo Bunkyoku, Tokyo 113-0033, Japan.

E-mail: jas_office@j-athero.or.jp
} 
CEREBRO- CARDIOVASCULAR DISEASE EPIDEMIOLOGY AND RISK EVALUATION IN JAPAN

Full-scale epidemiological research on cerebro- cardiovascular diseases in Japan began in the 1960s when stroke was the leading cause of death. The aim then was to investigate the actual conditions of stroke onset and associated risk factors, and thereby to use the results for prevention. Since then, various epidemiological studies have been conducted throughout Japan. From the 1980s, those studies have developed into nationwide collaborations; and in recent years, the number of reports on stroke risk factors by international meta-analyses has increased.

The growth of epidemiological research on coronary artery disease had been slower in Japan because its incidence rate has been much lower than those in Western countries. However, since reports emerged in the 2000s that incidence rates had increased significantly in urban areas, risk factors have gradually been clarified, mainly by means of urban or nationwide collaborative studies.

Important cerebro- cardiovascular risk factors are thought to include hypertension, hypo-HDL cholesterolemia (or high total cholesterol, high non-HDL cholesterol levels), hyper-LDL cholesterolemia, diabetes

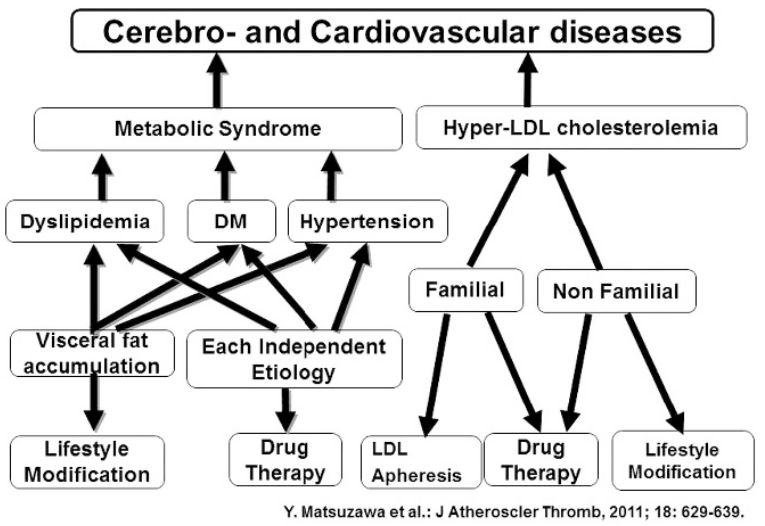

Figure 1 Comprehensive management of lifestyle habits and risk factors. (impaired glucose tolerance), smoking, excessive drinking, obesity, and CKD. Accordingly, it is appropriate to set the following eight risk factors that require special attention for the prevention of cerebrocardiovascular diseases: (1) smoking, (2) hypertension, (3) diabetes (including impaired glucose tolerance), (4) dyslipidemia, (5) CKD, (6) obesity (visceral fat accumulation in particular), (7) age/gender (male or post-menopausal female), and (8) family history. Furthermore, it is also valid to perform risk management taking the overlapping presence of these factors into account.

Cardiovascular disease (coronary artery disease such as angina pectoris, myocardial infarction, etc.) risk factors

The mortality rate from cardiovascular disease in Japan is reported to be the lowest of all developed nations. However, it is anticipated that changes in diet and lifestyles over recent years will increase the incidence and mortality rates from cardiovascular disease in the near future. Table 1 shows risk factors for coronary artery disease in Japanese people cited in the 'Guidelines for the Primary Prevention of Ischemic Heart Disease (2012 revised edition)' by the Japanese Circulation Society.

Cerebrovascular disease (cerebral infarction, cerebral hemorrhage, subarachnoid hemorrhage etc.) risk factors (including cardiogenic cases)

Stroke is generally classified into cerebral infarction, cerebral hemorrhage, and subarachnoid hemorrhage. Of these, cerebral infarction is now the most common subtype in Japan (Figure 2). There is a marked increase in the hospitalization rate of cerebral infarction among person older than 70 years. Improved treatment and prevention of stroke is national health priorities because the aim is not just life prolongation but healthy longevity. Some of risk factors for stroke vary among stroke subtypes.

\section{DIAGNOSIS OF CHRONIC KIDNEY DISEASE (CKD) IN THE PREVENTION OF CEREBRO- CARDIOVASCULAR DISEASES}

Screening for CKD is one of the important items in the prevention of cerebro- cardiovascular disease.

Table 1 Risk factors for coronary artery disease in Japanese people

\begin{tabular}{|c|c|}
\hline Age & Men aged $\geqslant 45$ years or a women aged $\geqslant 55$ years \\
\hline Family history & Family history of premature CAD in first-degree relative \\
\hline \multicolumn{2}{|l|}{ Smoking } \\
\hline \multirow[t]{3}{*}{ dyslipidemia } & $\geqslant 140$ mg/dL Hyper-LDL cholesterolemia \\
\hline & $<40$ mg/dL Hypo-HDL cholesterolemia \\
\hline & $\geqslant 150$ mg/dL Hypertriglyceridemia \\
\hline Hypertension & Systolic blood pressure $\geqslant 140 \mathrm{mmHg}$ and/or diastolic blood pressure $\geqslant 90 \mathrm{mmHg}$ \\
\hline \multirow[t]{8}{*}{ Diabetes (including abnormal glucose tolerance), } & 1. Early-morning fasting blood glucose level: $\geqslant 126$ mg/dL \\
\hline & 2. Two-hour blood glucose level after 75 g glucose loading: $\geqslant 200 \mathrm{mg} / \mathrm{dL}$ \\
\hline & 3. Random(casual) blood glucose measurements: $\geqslant 200 \mathrm{mg} / \mathrm{dL}$ \\
\hline & 4. $\mathrm{HbA} 1 \mathrm{c}(\mathrm{NGSP}): \geqslant 6.5 \%[\mathrm{HbA} 1 \mathrm{c}(\mathrm{JDS}): \geqslant 6.1 \%]$ \\
\hline & Category 'Diabetic type' is indicated when any of 1. to 4. are confirmed. \\
\hline & 5. Early-morning fasting blood glucose level: $<110 \mathrm{mg} / \mathrm{dL}$ \\
\hline & 6. Two-hour blood glucose level after 75 g glucose loading: $<140 \mathrm{mg} / \mathrm{dL}$ \\
\hline & Category 'Normal type' is indicated when 5. and 6. are both confirmed. \\
\hline Obesity & $\mathrm{BMI} \geqslant 25$ or waist circumference: men $\geq 85 \mathrm{~cm}$, women $\geq 90 \mathrm{~cm}$ \\
\hline \multirow[t]{5}{*}{ Metabolic syndrome } & Waist circumference: men $\geq 85 \mathrm{~cm}$, women $\geq 90 \mathrm{~cm}$ \\
\hline & Two or more of the items mentioned below in addition to the above \\
\hline & Hypertriglyceridemia $\geqslant 150 \mathrm{mg} / \mathrm{dL}$ and/or Hpyo-HDL-cholesterolemia $<40 \mathrm{mg} / \mathrm{dL}$ for both men and women \\
\hline & Systolic blood pressure $\geqslant 130 \mathrm{mmHg}$ and/or diastolic blood pressure $\geqslant 85 \mathrm{mmHg}$ \\
\hline & Fasting hyperglycemia $\geqslant 110 \mathrm{mg} / \mathrm{dL}$ \\
\hline CKD & eGFR $<60 \mathrm{~mL} / \mathrm{min} / 1.73 \mathrm{~m} 2$ or albuminuria continuing for at least 3 months) \\
\hline Psychological stress & \\
\hline
\end{tabular}

Modified from Guidelines for the primary prevention of ishmeic heart disease revised version (JCS 2012) 

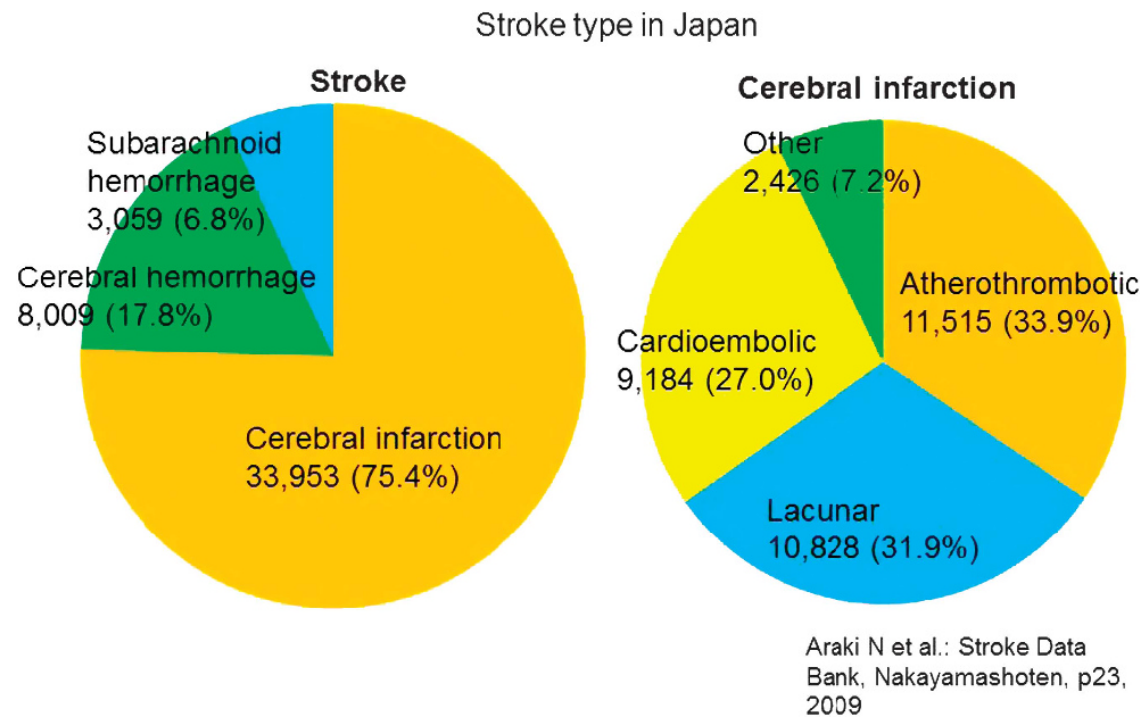

Figure 2 Stroke types in Japan.

The 'Evidence-based Clinical Practice Guideline for CKD'1 published in 2013 by the Japanese Society of Nephrology indicates that CKD is renal impairment as determined by the following criteria: either (1) Kidney damage is clearly present on the basis of urine test, diagnostic imaging, blood tests, or histological examination. The presence of proteinuria $\geqslant 0.15 \mathrm{~g} / \mathrm{gCr}$ (albuminuria $\geqslant 30 \mathrm{mg} / \mathrm{gCr}$ ) is of particular importance; or (2) glomerular filtration rate (GFR) $<60 \mathrm{ml} / \mathrm{min} / 1.73 \mathrm{~m}^{2}$; or both (1) and (2) are lasting for at least three months. As shown in international large-scale epidemiological studies including those in Japan, ${ }^{2}$ the risk of composite outcome including both end-stage renal disease and cerebro- cardiovascular disease is higher with more severe albuminuria and lower eGFR.

\section{DIAGNOSIS OF PERIPHERAL ARTERY DISEASE (PAD) IN THE} PREVENTION OF CEREBRO- CARDIOVASCULAR DISEASES

Peripheral artery disease (PAD) involves stenosis and constrictive lesions due to atherosclerosis of the peripheral blood vessels. Symptoms such as coldness in the legs, intermittent claudication, ulceration, and necrosis may be observed. In this management chart for the prevention of cerebro- cardiovascular diseases, the above symptoms need to be confirmed in Step la of screening. If the ankle-brachial index (ABI), one of the additional evaluation items in Step $1 \mathrm{~b}$ screening, is $<0.9$ or $\geqslant 1.3, \mathrm{PAD}$ is suspected. If there is a history of $\mathrm{PAD}$ or complications are suspected, it should be considered to refer the patient to a physician specialist. Patients with PAD have high incidence and mortality rates for coronary artery disease and stroke. According to TASC-II, half of PAD patients had coronary artery disease.

\section{IMPROVEMENT OF LIFESTYLE HABITS TO PREVENT CEREBRO- CARDIOVASCULAR DISEASES}

Quitting smoking

It is necessary to determine during risk evaluation screening whether the patient has a smoking habit to prevent cerebro- cardiovascular diseases. Any deleterious lifestyle habits, such as smoking and passive smoking, should be first improved during treatment after diagnosing and evaluating risk factors and setting management objectives. Quitting smoking decreases mortality and lowers cardiovascular disease risk, regardless of whether the person has a history of coronary artery disease, and these effects are independent of age and gender. Moreover, effects appear quickly after quitting; the longer the non-smoking period is, the further the risks decrease. ${ }^{3}$ Smoking is also a risk factor for exacerbating heart failure. ${ }^{4}$ Accordingly, when aiming to prevent cerebro- cardiovascular diseases, all smokers must first be encouraged to quit.

\section{Diet therapy}

Cerebro- cardiovascular diseases develop due to lifestyle habits such as overeating and lack of physical activity in addition to genetic factors. Historically, strokes were common and coronary artery disease relatively uncommon in Japan. In recent years, there has been a marked decrease in the number of strokes. However, the Hisayama study also found that the cerebro- cardiovascular risk factors such as obesity, and abnormal glucose tolerance, and hypercholesterolemia are increasing in both men and women, whereas hypertension incidence and smoking rates are decreasing. Meanwhile, the National Health and Nutrition Survey in Japan found that consumption of whole grains and rice was markedly decreasing, whereas the consumption of milk, dairy products, and meat was increasing, demonstrating the Westernization of diets in Japan. The Japan Atherosclerosis Society summarized evidence related to the traditional Japanese diet to recommend 'The Japan Diet' with reduced sodium intake in the 2012 edition of the Guidelines for Prevention of Atherosclerotic Cardiovascular Diseases.

\section{Exercise therapy}

Physical activity (daily activity and exercise) plays an important role in the primary and secondary prevention of atherosclerotic cardiovascular disease through changes in metabolism and in the musculoskeletal system, and inhibition of chronic inflammation. In order to perform physical activity, an amount and quality of exercise that exceeds that of daily life are necessary, and thus appropriate guidance is required, while taking individual risks into account. This management chart recommends 'to regularly engage in moderate to vigorous aerobic exercise (at least $30 \mathrm{~min}$ per day).'

\section{MANAGEMENT OF EACH RISK FACTOR -GOAL OF MANAGEMENT-}

\section{Blood pressure management}

Basic elements of blood pressure management are accurate diagnosis and monitoring of blood pressure values. This management chart 


\begin{tabular}{l|l|}
\cline { 2 - 3 } Diabetic Type & Fasting plasma glucose $\geq 126 \mathrm{mg} / \mathrm{dL}$; or OGTT 2 hours $\geq 200 \mathrm{mg} / \mathrm{dL}$; or random (casual) plasma glucose $\geq 200 \mathrm{mg} / \mathrm{dL}$ \\
HLA $1 \mathrm{C}$ (NGSP) $\geq 6.5 \%[\mathrm{HbA} \cdot \mathrm{C}(\mathrm{JDS}) \geq 6.1 \%]^{* 1}$
\end{tabular}

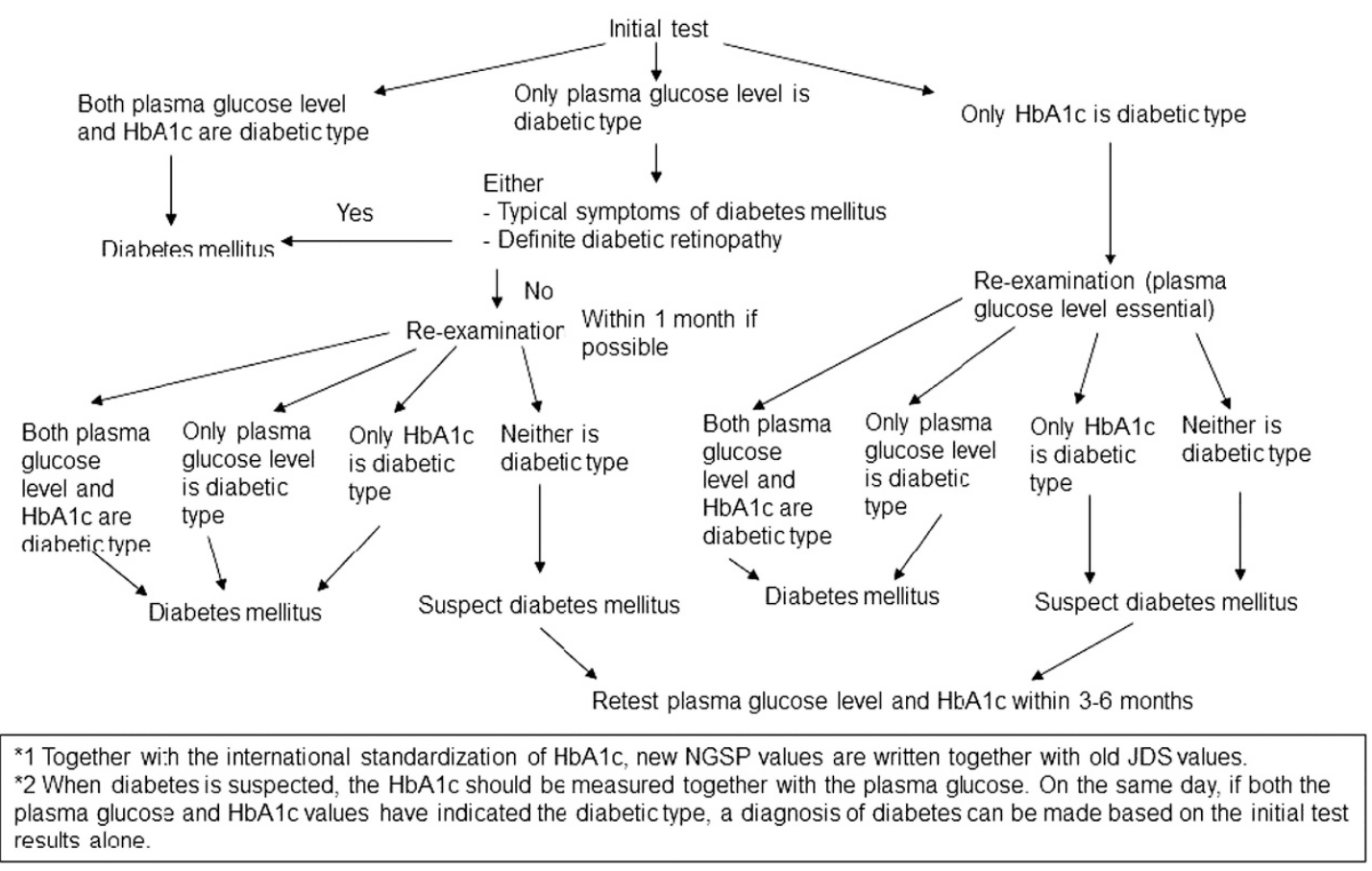

Figure 3 Flowchart for the clinical diagnosis of diabetes.

includes home blood pressure in the medical interview and clinic blood pressure as a physical finding in Step 1a, orthostatic blood pressure in Step $1 \mathrm{~b}$, and 24-hour blood pressure as an additional evaluation item in Step 2. Diagnosing the cause of hypertension is also included in the first step. In the management chart, in order to differentiate from secondary hypertension, Step $1 \mathrm{~b}$ includes plasma aldosterone concentration/renin activity ratio measurement, taking frequency and importance into account and Step 1c includes screening for cases suspected of juvenile-onset and sudden onset. Blood pressure goals range from strict to moderate depending on complications and age. The basic stance taken when selecting anti-hypertensive agents is to proactively confirm the compelling indications and, if they are not eligible for a certain agent; a calcium channel blocker, an angiotensinconverting enzyme inhibitor, an angiotensin receptor blocker, or a diuretic, to choose the first-line agent. One must also take precautions in cases of women who might be pregnant.

\section{Glycemic control}

Cerebro- cardiovascular diseases occur at a much higher rate in patients with diabetes due to chronic hyperglycemia and/or insulin resistance, which can trigger and facilitate atherosclerotic processes by various mechanisms such as oxidative stress, nonenzymatic glycosylation, chronic inflammation, lipoprotein abnormalities, and vascular endothelial dysfunction. It is necessary to prove a chronic hyperglycemic status to diagnose diabetes mellitus, so as a rule it is necessary to re-confirm that the patient is 'diabetic type' on tests performed on separate days. However, diabetes mellitus can be diagnosed on the basis of the initial test alone if blood glucose levels and HbAlc values are measured simultaneously and it can be confirmed that both show the patient to be diabetic type. Alternatively, when patients who are classified as diabetic type by blood glucose level exhibit typical symptoms such as thirst, polydipsia, polyuria, and weight loss, a diagnosis can be made on the basis of the initial test alone (Figure 3). It is recommended to aim for $\mathrm{HbAlc}<7 \%$ (roughly equivalent to fasting blood glucose levels below $130 \mathrm{mg} / \mathrm{dl}$ ) as a basic goal for preventing complications, particularly microangiopathy. However, as stated above, there is an increased risk of macroangiopathy even in the stage of impaired glucose tolerance. Therefore, from the viewpoint of preventing cerebro- cardiovascular diseases, if $\mathrm{HbAlc}<6 \%$ can be achieved without any side effects such as hypoglycemia using appropriate diet therapy and exercise therapy alone or with the addition of pharmacotherapy, it is recommended that goal for glycemic control should be set to below $6 \%$. Alternatively, when it is difficult to intensify the treatment due to side effects such as hypoglycemia or other reasons, a target $\mathrm{HbAlc}$ of $8 \%$ could be set (Table 2).

\section{Lipid management}

To prevent the onset of cerebro- cardiovascular diseases, it is important to manage dyslipidemia. Since this management chart mainly targets primary prevention patients (without coronary artery disease) examined by physician specialists, lipid management target values classified by risk are determined as target values for LDL-C, HDL-C, TG, etc. in accordance with the management category classification I-III. Lipid management target values are set on the basis of category classification. LDL-C management target values are $<160 \mathrm{mg} / \mathrm{dl}$ for category I (estimated 10-year risk of CAD death rate $<0.5 \%$ ), $<140 \mathrm{mg} / \mathrm{dl}$ for category II (estimated 10-year risk of CAD death rate $0.5-2.0 \%$ ), and $<120 \mathrm{mg} / \mathrm{dl}$ for category III (estimated 10 -year risk of $\mathrm{CAD}$ death rate $\geqslant 2.0 \%$ and the patients with $\mathrm{CKD}$, $\mathrm{DM}$, cerebro- cardiovascular diseases and PAD). 
Table 2 Glycemic control targets

\begin{tabular}{lccc}
\hline \multirow{2}{*}{ Targets } & \multicolumn{2}{c}{ Control goals $^{\mathrm{a}}$} & \\
\cline { 2 - 4 } & Target when aiming for normal glycemia $^{\mathrm{b}}$ & Target when aiming to prevent complication $^{\mathrm{c}}$ & Target when intensification of therapy considered difficult $^{\mathrm{d}}$ \\
\hline HbAlc (\%) & $<6.0$ & $<7.0$ & $<8.0$
\end{tabular}

*This diagram shows NGSP values for HbAlc.

Treatment targets are established individually, in consideration of age, duration of disease, organ damage, risk of hypoglycemia, support structures, etc.

aAll target values are for adults, not including pregnant women.

${ }^{b}$ Target can be attained by appropriate dietary or exercise therapy, or during pharmacotherapy without the occurrence of side effects such as hypoglycemia.

cFrom the perspective of preventing complication, $\mathrm{HbAlc}$ target is set below $7 \%$. Corresponding glycemic targets are set at roughly below $130 \mathrm{mg} / \mathrm{dL}$.

dWhen intensification of treatment is considered difficult due to side effects such as hypoglycemia or for other reasons.

Japan Diabetes Society, Treatment Guide for Diabetes 2014-2015

Table 3 Step 1 additional interview items in medical questionnaire

\begin{tabular}{|c|c|c|}
\hline \multicolumn{2}{|c|}{ Patient ID } & Name \\
\hline \multicolumn{2}{|c|}{ Questionnaire } & Options *1 \\
\hline 1 & $\begin{array}{l}\text { Are you taking medicines to reduce blood pressure, } \\
\text { blood glucose or blood cholesterol? }\end{array}$ & $\begin{array}{l}\square \text { Any of them } \\
\square \text { None of them }\end{array}$ \\
\hline 2 & $\begin{array}{l}\text { Do you have loud and frequent snoring? Do you have } \\
\text { pauses in breathing or shallow breaths while you sleep? } \\
\text { Do you have chronic daytime fatigue or sleepiness? }\end{array}$ & $\begin{array}{l}\square \text { Any of them } \\
\square \text { None of them }\end{array}$ \\
\hline 3 & $\begin{array}{l}\text { Do you inhale secondhand cigarette smoke at your } \\
\text { office or home? }\end{array}$ & $\begin{array}{l}\square \text { Yes } \\
\square \text { No }\end{array}$ \\
\hline \multicolumn{3}{|c|}{$\begin{array}{l}\text { Medical history of your grandfather/grandmother, } \\
\text { father/mother, or siblings }\end{array}$} \\
\hline 4 & $\begin{array}{l}\text { Currently taking medicines to reduce blood pressure, } \\
\text { blood glucose or blood cholesterol? }\end{array}$ & $\begin{array}{l}\square \text { Medicines to reduce blood } \\
\text { pressure } \\
\square \text { Medicines to reduce blood } \\
\text { glucose } \\
\square \text { Medicines to reduce blood } \\
\text { cholesterol *2 } \\
\square \text { Others }\end{array}$ \\
\hline 5 & $\begin{array}{l}\text { Have been told to have disease and took medicines to } \\
\text { reduce blood pressure, blood glucose or blood } \\
\text { cholesterol? }\end{array}$ & $\begin{array}{l}\square \text { Stroke (cerebral infarction or } \\
\text { hemorrhage) or TIA } \\
\square \text { Coronary artery disease } \\
\text { (Myocardial infarction } \\
\text { or Angina pectoris) } \\
\square \text { Chronic kidney disease or } \\
\text { hemodialysis } \\
\square \text { Diabetes } \\
\square \text { Others }\end{array}$ \\
\hline
\end{tabular}

*1 You May Choose Multiple Options

*2 Includes Medicine to reduce Triglyceride

\section{Obesity management}

In Japan, obesity is defined as a BMI of 25 or higher. When BMI reaches 25 , the prevalence of hypertension and dyslipidemia is twice than those at BMI 22 at which the prevalence of both is considered to be lowest. ${ }^{5}$ However, increases in cardiovascular disease risk are more strongly affected by excessive accumulation of visceral fat than the degree of obesity as determined by BMI. As more visceral fat is accumulated in men than in women, the prevalence and mortality rates from diabetes and dyslipidemia are higher in men than in women even at the same BMI. As a screening test for the excessive 
accumulation of visceral fat, waist circumference is measured at the umbilical level and excessive accumulation is suspected to be present for men who measure $85 \mathrm{~cm}$ or greater and for women who measure $90 \mathrm{~cm}$ or greater. With visceral fat accumulation as a mandatory item, metabolic syndrome is diagnosed if the patient has at least two of the following: hyperglycemia, dyslipidemia, or hypertension. In cases of metabolic syndrome, the accumulation of cardiovascular risk factors other than cholesterol caused by obesity leads to the onset of atherosclerosis, followed by cerebro- cardiovascular diseases. Visceral fat decreases more quickly than subcutaneous fat with weight loss therapy. ${ }^{6}$ The target of weight loss therapy is 3\% reduction of the body weight, if the BMI is 25 or greater.

\section{HOW TO USE THE COMPREHENSIVE MANAGEMENT CHART FOR CEREBRO- CARDIOVASCULAR DISEASES (ALGORITHM)}

As shown on the first page, this comprehensive management chart for cerebro- cardiovascular diseases mainly targets patients at hospital who were diagnosed as having a high risk of cerebro- cardiovascular diseases during a routine health checkup and does not target secondary prevention. However, it has been created as a tool that can also be used to evaluate the management status of patients already undergoing treatment of risk factors.

(1) Algorithm outline

This management chart was designed so that physician specialists can easily conduct diagnosis and treatment in accordance with the procedures from Steps 1 through 6. We tried to ensure mutual consistency with related academic society guidelines and treatment guidelines. Step 1 comprises screening and diagnostic criteria for the necessity of referral to a physician specialist. Step 2: diagnosis of risk factors and additional evaluation items. Step 3: risk factors that need to be confirmed before starting treatment. Step 4: the setting of management goal in accordance with risk and the pathological condition of each individual patient. Step 5: lifestyle habit improvement. Step 6: the introduction of pharmacotherapy and points of caution.

(2) Step 1

Step 1 comprises Step 1a and Step 1b, which lists basic and additional items for screening, respectively, and Step 1c, which presents diagnostic criteria for the necessity of referral to a physician specialist. In Step 1a, items queried by medical interview include home blood pressure in addition to standard items from the 'Tokutei Kensin' (Tokutei Kensin: nationwide annual health check, which is recommend for all residents of Japan aged between 40 and 74 years by the Ministry of Health, Labour and Welfare) such as age/gender, subjective symptoms, family history, complications/medical history, medication history, lifestyle habits (smoking, alcohol), exercise habits, and sleep. Furthermore, an additional medical interview item questionnaire including items thought to be strongly associated with cerebro- cardiovascular disease risk such as family history and passive smoking were newly created (Table 3). The physical findings included height, weight, BMI (body weight $[\mathrm{kg}]$ divided by height $[\mathrm{m}]^{2}$ ), clinic blood pressure, pulse rate/min (normal/arrhythmia), and chest auscultation. Moreover, it is recommended that blood tests should ideally be performed during fasting if possible. Test items comprise TC, HDL-C, non-HDL-C (TC-HDL-C), eGFR (serum creatinine), ALT, $\gamma$-GT, HbAlc, and blood glucose (either HbAlc or blood glucose only for the 'diabetic type' [in the event that HbAlc $\geqslant$ $6.5 \%$ or fasting blood glucose of $\geqslant 126 \mathrm{mg} / \mathrm{dl}$, or casual blood glucose level of $\geqslant 200 \mathrm{mg} / \mathrm{dl}$ is indicated, re-test shall be performed on a separate day]). It is also recommended to perform general (qualitative) urine testing and electrocardiography with referral to a physician specialist depending on the degree of abnormality, such as atrial fibrillation.

Step $1 \mathrm{~b}$ shall be implemented in the additional screening item simultaneously with Step 1a or after an abnormality is noted in 1a. The items examined are waist circumference, orthostatic blood pressure (after 1-3 min of standing), ABI, limb (artery) palpation, cervical vascular murmur, and abdominal vascular murmur. In contrast to the test items in Step 1a, blood samples shall be collected during fasting and blood counts, fasting blood glucose, fasting TG, LDL-C shall be calculated (make sure to simultaneously test TC, HDL-C and TG during fasting and if $\mathrm{TG}<400 \mathrm{mg} / \mathrm{dl}_{\text {s }}$ calculate LDL-C using the Friedewald formula (or equation) (TC $-\mathrm{HDL}-\mathrm{C}-0.2 \times \mathrm{TG})$ ). Furthermore, in addition to measurements of uric acid and potassium concentrations, plasma aldosterone concentration/renin activity ratio shall be measured and chest X-rays acquired. If an abnormality is noted during spot urine quantification or general qualitative urine test, the albuminuria/creatinine ratio shall be measured. In Step 1c, we outlined the state in which referral to a physician specialist is required from the above screening.

(1) History or suspected complications of stroke/transient ischemic attack (TIA), coronary artery disease, arrhythmia such as atrial fibrillation, aortic disease, PAD.

(2) For hypertensive patients, suspected secondary hypertension (juvenile-onset, sudden onset, etc.), pregnancy-induced hypertension, suspected hypertensive emergency/hypertensive urgency (untreated diastolic blood pressure $\geqslant 120 \mathrm{~mm} \mathrm{Hg}$, $\geqslant 180 / 110 \mathrm{~mm} \mathrm{Hg}$ if treated, or target blood pressure not achieved even with triple drug therapy).

(3) For diabetes, type 1 diabetes, HbAlc $\geqslant 8.0 \%$, fasting blood glucose $\geqslant 200 \mathrm{mg} / \mathrm{dl}$ (or spot blood glucose $\geqslant 300 \mathrm{mg} / \mathrm{dl}$ ), acute complications (hyperglycemia emergency), and gestational diabetes.

(4) For dyslipidemia, LDL-C $\geqslant 180 \mathrm{mg} / \mathrm{dl}$, HDL-C $<30 \mathrm{mg} / \mathrm{dl}$, $\mathrm{TG} \geqslant 500 \mathrm{mg} / \mathrm{dl}$, non-HDL-C $\geqslant 210 \mathrm{mg} / \mathrm{dl}$, suspected primary hyperlipidemia, suspected secondary dyslipidemia.

(5) For $\mathrm{CKD}$, proteinuria (albuminuria/creatinine ratio $\geqslant 0.5 \mathrm{~g} / \mathrm{gCr}$, or urine dipstick test $\geqslant 2+$ ), both albuminuria and hematuria positive (urine dipstick test $\geqslant 1+$ ), eGFR $<50 \mathrm{ml} / \mathrm{min} / 1.73 \mathrm{~m}^{2}$ ( $<60$ if younger than 40 years, $<40$ for patients aged 70 years or older with stable kidney function).

(6) For obesity, severe obesity (BMI $\geqslant 35)$ or suspected secondary obesity (symptomatic obesity).

(3) Step 2

Step 2 involves diagnosis of each risk factor and additional evaluation items.

(1) For hypertension (clinic blood pressure $\geqslant 140 / 90 \mathrm{~mm} \mathrm{Hg}$ or home blood pressure $\geqslant 135 / 85 \mathrm{~mm} \mathrm{Hg}$ ), measure 24-hour blood pressure as necessary (with differentiation of nighttime hypertension and workplace hypertension).

(2) If suspected diabetes cannot be ruled out (HbAlc $5.6 \%-6.4 \%$, fasting blood glucose levels of $100-125 \mathrm{mg} / \mathrm{dl}$, or spot blood glucose levels of $140-199 \mathrm{mg} / \mathrm{dl}$ ), or if there is familial clustering of diabetes or presence of obesity, perform 75-g oral glucose tolerance test (OGTT) (however, this does not apply if clear diabetes symptoms are present). 
Table 4 Management categories based on sex, age, and number of risk factors

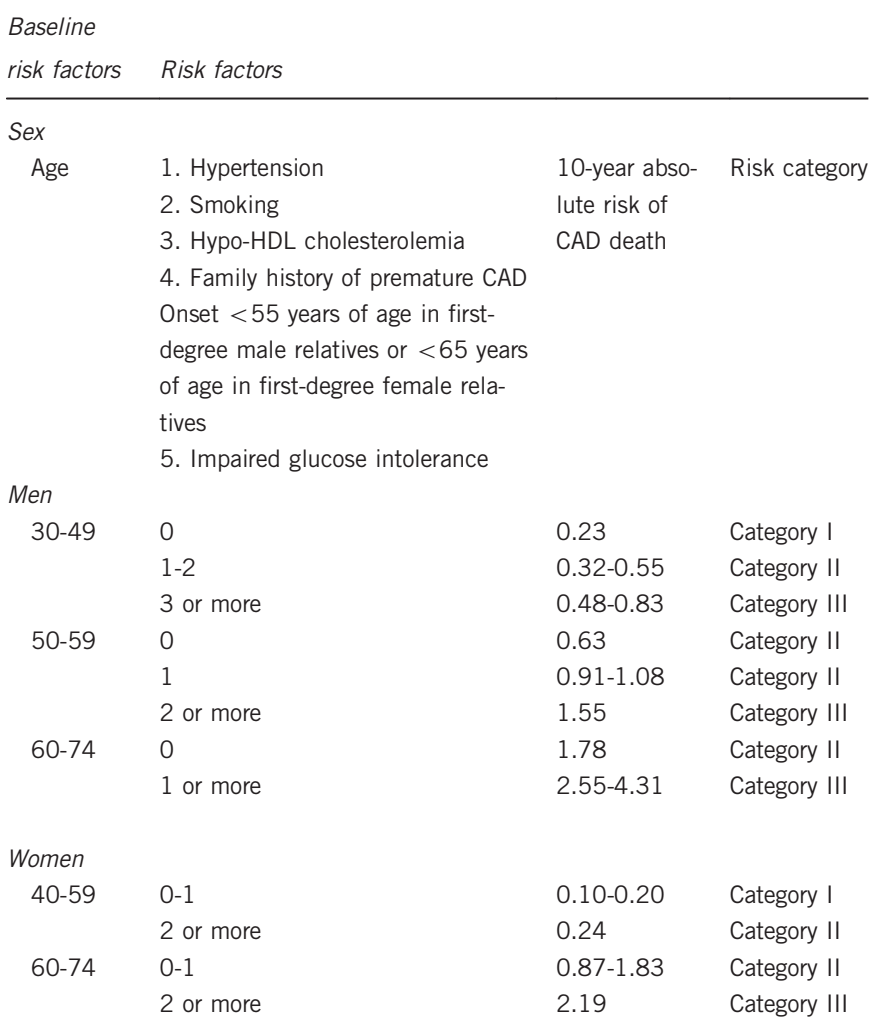

(Modified from Japan Atherosclerosis Society (JAS) Guidelines for the Diagnosis and Prevention of Atherosclerotic Cardiovascular Diseases in Japan-2012 Version).

(3) If clearly diagnosed with diabetes (if HbAlc and blood glucose levels both indicate diabetes and if diabetic polydipsia, polyuria, and weight loss are present) or the patient has clear diabetic retinopathy or was reconfirmed to be diabetic type on a test performed on a separate day (however, blood glucose levels must show diabetic type on either the initial test or the repeat test), funduscopy and albuminuria/ creatinine ratio measurement are performed (spot urine quantification) ${ }^{7}$

(4) For dyslipidemia (LDL-C $\geqslant 140 \mathrm{mg} / \mathrm{dl}$, HDL-C $<40 \mathrm{mg} / \mathrm{dl}$, fasting $\mathrm{TG} \geqslant 150 \mathrm{mg} / \mathrm{dl}$ or non HDL-C $\geqslant 170 \mathrm{mg} / \mathrm{dlL},{ }^{8}$ the presence of corneal ring, Achilles tendon hypertrophy, skin/tendon xanthoma, eruptive xanthoma shall be confirmed.

(5) $\mathrm{CKD}$ shall be diagnosed if eGFR $<60 \mathrm{ml} / \mathrm{min} / 1.73 \mathrm{~m}^{2}$ or albuminuria continuing for at least 3 months). ${ }^{1}$

(6) For metabolic syndrome, diagnosis shall be made on the basis of the diagnostic criteria of the eight of internal medicine societies (Japanese Society of Internal Medicine, Japan Society for the Study of Obesity, Japan Atherosclerosis Society, the Japan Diabetes Society, Japanese Society of Hypertension, Japanese Circulation Society, Japanese Society of Nephrology, and Japanese Society on Thrombosis and Hemostasis). ${ }^{9}$

(4) Step 3

Step 3 involves evaluation of risk factors that should be confirmed before starting treatment. These include (1) smoking, (2) hypertension, (3) diabetes (including impaired glucose tolerance), (4) dyslipidemia, (5) CKD, (6) obesity (visceral fat type obesity in particular), (7) age/gender (includes male or post-menopausal female), and (8) family history (grandfather/grandmother, father/ mother, sibling with history of or complication of cerebro- or cardiovascular disease or lifestyle disease [hypertension, diabetes, dyslipidemia, particularly juvenile-onset cases]). Whilst constantly keeping in mind that overlapping risk factors require strict management, these form the basis for risk management.

(5) Step 4

Step 4 involves setting management goal in accordance with risk factors and the clinical condition of individual patients. It is based on the guidelines of various academic societies. Management of elderly individuals shall be established taking lifestyle environment such as living alone/care status, and individual factors such as activities of daily living (ADL), cognitive function, and quality of life (QOL) into consideration.

\section{(1) Hypertension}

Younger than 75 years clinical blood pressure $<140 / 90 \mathrm{~mm} \mathrm{Hg}$ (home blood pressure $<135 / 85 \mathrm{~mm} \mathrm{Hg}$ )Age 75 years or older blood pressure $<150 / 90 \mathrm{~mm} \mathrm{Hg}$ (home blood pressure $<145 / 85 \mathrm{~mm} \mathrm{Hg}$ ). (If tolerable, blood pressure $<140 / 90 \mathrm{~mm} \mathrm{Hg}$ or home blood pressure $<135 / 85 \mathrm{~mm} \mathrm{Hg}$ ). For patients with diabetes or albuminuria-positive CKD complications: blood pressure $<130 / 80 \mathrm{~mm} \mathrm{Hg}$ (home blood pressure $<125 / 75 \mathrm{~mm} \mathrm{Hg}$ ).

(2) Diabetes

Target aiming for blood glucose normalization: HbAlc $<6.0 \%$.

Target for preventing complications: HbAlc $<7.0 \%$.

Target if difficult to intensify the treatment: $\mathrm{HbAlc}<8.0 \%$.

(3) Dyslipidemia.

For all risk categories, HDL-C $\geqslant 40 \mathrm{mg} / \mathrm{dl}$, TG $<150 \mathrm{mg} / \mathrm{dl}$. Furthermore,

Category I (low risk): LDL-C $<160 \mathrm{mg} / \mathrm{dl}$ (non-HDL-C $<190 \mathrm{mg} / \mathrm{dl}$ ).

Category II (moderate risk): LDL-C $<140 \mathrm{mg} / \mathrm{dl}$ (non-HDL-C $<170 \mathrm{mg} / \mathrm{dl}$ ).

Category III (high risk): LDL-C $<120 \mathrm{mg} / \mathrm{dl}$ (non-HDL-C $<150 \mathrm{mg} / \mathrm{dl})$.

When stratifying risk, the 2012 edition of the Guidelines for Prevention of Atherosclerotic Cardiovascular Diseases established by the Japan Atherosclerosis Society state that the following model obtained from a 'Simple Chart for Classification based on Gender, Age and Number of Risk Factors' (modified from Table 4) is recommended for use.

\begin{tabular}{|c|c|c|}
\hline \multicolumn{3}{|l|}{ Male } \\
\hline Risk factors* & $40-59$ years & $60-74$ years \\
\hline 1 & Category II & Category III \\
\hline 2 or more & Category II & Category III \\
\hline \multicolumn{3}{|l|}{ Female } \\
\hline Risk factors & 40-59 years & $60-74$ years \\
\hline 1 & Category I & Category II \\
\hline 2 or more & Category II & Category III \\
\hline
\end{tabular}

*Risk factors include smoking, hypertension, hypo-HDL cholesterolemia, family history, and impaired glucose tolerance.

(Note) A patient with a history or complications of diabetes, CKD, cerebral infarction, or PAD is classified as high risk regardless of age or gender. 
(4) Obesity

Improvement of hypertension, diabetes, and dyslipidemia by a $3-5 \%$ decrease in bodyweight.

(6) Step 5

Step 5 emphasizes lifestyle modification-in particular, quitting smoking, diet management, weight management, physical activity/ exercise, and moderation in alcohol consumption. With regards to physical activity, METs is a unit for activity intensity that shows how much the activity equates to metabolism during sitting quietly. Activity of moderate intensity or greater is defined as an intensity of 3 METs or greater. Normal walking is equivalent to 3 METs, fast walking is 4 METs, and jogging is 7 METs. Individuals with no exercise habit shall be advised to start with light exercise or exercise for a short period of time. Ethanol $(25 \mathrm{~g})$ is equivalent to 1 glass of Japanese sake, one medium glass of beer, half a cup of shochu, one double-shot of whiskey or brandy, or two glasses of wine.

(7) Step 6

Step 6 describes pharmacotherapy. It is emphasized that with continuing lifestyle modification, pharmacotherapy should be started or continued with careful consideration of individual risk factors and disease pathology. However, when there is a high risk, the necessity of strict pharmacotherapy is also emphasized.

The details of pharmacotherapy shall be conducted in accordance with the guidelines for each disease.

For elderly patients aged 75 years or older or patients with renal dysfunction, particular care should be taken for side effects caused by drugs.

The selection of drugs for each of the diseases and points of caution are suggested on page 4 of this management chart along with the table, and thus it is encouraged to use them as reference.

\section{PARTICIPATING SOCIETIES AND ORGANIZATIONS}

The Japanese Society of Internal Medicine, the Japan Epidemiological Association, the Japanese Society of Hypertension, the Japanese Circulation Society, the Japanese Society of Nephrology, the Japanese Society of Physical Fitness and Sports Medicine, the Japan Diabetes Society, the Japan Atherosclerosis Society, the Japan Stroke Society, the Japan Society for the Study of Obesity, the Japan Geriatrics Society, the Japanese Association of Medical Sciences, and the Japan Medical Association.

\section{WRITING COMMITTEE}

Tamio Teramoto, Masayuki Yokode, Hiroyasu Iso, Akihiko Kitamura, Hiroki Shiomi, Tsuyoshi Kimura, Masayasu Matsumoto, Mami Iida, Jun Sasaki, Shigeru Inoue, Ryouichi Nagatomi, Tetsuo Shoji, Hidenori Arai, Hiromi Rakugi, Hirohito Sone, Shizuya Yamashita, Shigeru Mizyzaki.

\section{CONFLICT OF INTEREST}

Tamio Teramoto: honoraria from Astellas Pharma Inc., Kowa Pharmaceutical Company Ltd., Daiichi Sankyo Company, Limited, Takeda Pharmaceutical Company Limited, Bayer Yakuhin, Ltd. and Pfizer Japan Inc.; research funding from ASKA Pharmaceutical Co., Ltd., Kissei Pharmaceutical Co., Ltd., Kowa Pharmaceutical Company Ltd., Bayer Yakuhin, Ltd. and Mochida Pharmaceutical Co., Ltd. Masayuki Yokde: research funding from Otsuka Pharmaceutical Co., Ltd.; donation from Daiichi Sankyo Company, Limited. Tsuyoshi Kimura: honoraria from Astellas Pharma Inc., AstraZeneca K.K., Abbott Vascular Japan Co., Ltd., MSD K.K., Kowa Pharmaceutical Company Ltd., Sanofi K.K., Daiichi
Sankyo Company, Limited, Pfizer Japan Inc.; research funding from Daiichi Sankyo Company, Limited, Toray Medical Co., Ltd., Heart Flow; donation from Abbott Vascular Japan Co., Ltd., MSD K.K., Sanofi K.K., Daiichi Sankyo Company, Limited, Takeda Pharmaceutical Company Limited, Novartis Pharma K.K. Masayasu Matsumoto: honoraria from Eisai Co., Ltd., Otsuka Pharmaceutical Co., Ltd., Sanofi K.K., Daiichi Sankyo Company, Limited, Sumitomo Dainippon Pharma Co., Ltd., Takeda Pharmaceutical Company Limited, Nippon Boehringer Ingelheim Co., Ltd., Bayer Yakuhin, Ltd., Mochida Pharmaceutical Co., Ltd.; donation from Otsuka Pharmaceutical Co., Ltd., Sanofi K.K., Daiichi Sankyo Company, Limited, Takeda Pharmaceutical Company Limited, Nippon Boehringer Ingelheim Co., Ltd., Mochida Pharmaceutical Co., Ltd. Hidenori Arai: employment/leadership position/advisory role; Possible Medical Science; honoraria from MSD K.K., Kowa Pharmaceutical Company Ltd., Daiichi Sankyo Company, Limited; donation from Otsuka Pharmaceutical Co., Ltd., Daiichi Sankyo Company, Limited. Hiromi Rakugi: honoraria from Astellas Pharma Inc., MSD K.K., Kyowa Hakko Kirin Co., Ltd., Shionogi \& Co., Ltd., Daiichi Sankyo Company, Limited, Sumitomo Dainippon Pharma Co., Ltd., Takeda Pharmaceutical Company Limited, Nippon Boehringer Ingelheim Co., Ltd., Novartis Pharma K.K., Pfizer Japan Inc., Mochida Pharmaceutical Co., Ltd.; honoraria from MSD K.K., Yowa Hakko Kirin Co., Ltd.; research funding from Novartis Pharma K.K.; donation from Astellas Pharma Inc., MSD K.K., Kyowa Hakko Kirin Co., Ltd., Shionogi \& Co., Ltd., Daiichi Sankyo Company, Limited, Sumitomo Dainippon Pharma Co., Ltd., Takeda Pharmaceutical Company Limited, Nippon Boehringer Ingelheim Co., Ltd., Novartis Pharma K.K., Pfizer Japan Inc. Hirohito Sone: honoraria from Astellas Pharma Inc., Ono Pharmaceutical Co., Ltd., Kowa Pharmaceutical Company Ltd., Sanofi K.K., Sanwa Kagaku kenkyusho Co., Ltd., Daiichi Sankyo Company, Limited, Mitsubishi Tanabe Pharma Corporation, Nippon Boehringer Ingelheim Co., Ltd., Novartis Pharma K.K., Novo Nordisk Pharma Ltd.; research funding: Novo Nordisk Pharma Ltd.; donation from Asahi Kasei Pharma Corporation, Astellas Pharma Inc., Eisai Co., Ltd., MSD K.K., Otsuka Pharmaceutical Co., Ltd., Kyowa Hakko Kirin Co., Ltd., Sanofi K.K., Daiichi Sankyo Company, Limited, Taisho Toyama Pharmaceutical Co., Ltd., Sumitomo Dainippon Pharma Co., Ltd., Takeda Pharmaceutical Company Limited, Mitsubishi Tanabe Pharma Corporation, Eli Lilly Japan K.K., Japan Blood Products Organization, Nippon Boehringer Ingelheim Co., Ltd., Novartis Pharma K.K., Pfizer Japan Inc., Meiji Seika Pharma Co., Ltd., Yakult Honsha Co., Ltd. Shizuya Yamashita: honoraria from MSD K.K., Kowa Company, Ltd., Kowa Pharmaceutical Company Ltd., Sanwa Kagaku Kenkyusho Co., Ltd., Takeda Pharmaceutical Company Limited, Bayer Yakuhin, Ltd.; research funding from National Institute of Biomedical Innovation, Otsuka Pharmaceutical Co., Ltd., Ono Pharmaceutical Co., Ltd., Kyowa Medex Co., Ltd., Kowa Pharmaceutical Company Ltd., Sanwa Kagaku Kenkyusho Co., Ltd., Shionogi \& Co., Ltd., Nippon Boehringer Ingelheim Co., Ltd., Bayer Yakuhin, Ltd.; donation from Astellas Pharma Inc., AstraZeneca K.K., MSD K.K., Sanwa Kagaku Kenkyusho Co., Ltd., Daiichi Sankyo Company, Limited, Takeda Pharmaceutical Company Limited, Mochida Pharmaceutical Co., Ltd.

1 Japanese Society of Nephrology. Evidence-based Practice Guideline for the Treatment for CKD in Japan 2013. Tokyo Igakusha: Tokyo.

2 Chronic Kidney Disease Prognosis Consortium, Matsushita K, van der Velde M, Astor BC, Woodward M, Levey AS, de Jong PE, Coresh J, Gansevoort RT. Association of estimated glomerular filtration rate and albuminuria with: all-cause and cardiovascular mortality in general population cohorts: a collaborative meta-analysis. Lancet 2010; 375: 2073-2081.

3 Iso H, Date C, Yamamoto A, Toyoshima H, Watanabe Y, Kikuchi S, Koizumi A, Wada Y, Kondo T, Inaba Y, Tamakoshi Athe JACC Study Group. Smoking cessation and mortality from cardiovascualr disese among Japanese men and women: the JACC Study. Am J Epidemiol 2005; 161: 170-179.

4 Suskin N, Sheth T, Negassa A, Yusuf S. Relationship of current and past smoking to mortality and morbidity in patient with left ventricular dysfunction. J Am Coll Cardiol 2001; 37: 1677-1682.

5 Yoshiike N et al. Journal of Japan Society for the study of Obesity 2000; 6: 4-17.

6 Suzuki R, Watanabe S, Hirai Y, Akiyama K, Nishide T, Matsushima Y, Murayama H, Ohshima H, Shinomiya M, Shirai K, Saito Y, Yoshida S, Saisho H, Ohto M. Abdominal wall fat index, estimated by ultrasonography, for assessment of ratio of visceral fat to subchtaneous fat in the abdomen. Am J Med 1993; 95: 309-314. 
7 Evidence-based Practice Guideline for the Treatment for Diabetes in Japan 2013.

8 Japan Atherosclerosis Society (JAS) Guidelines for Prevention of Atherosclerotic Cardiovacular Diseases 2012.
9 Committee on Diagnostic Criteria for Metabolic Syndrome. Definition and diagnostic criteria of metabolic syndrome. J Jpn Soc Intern Med 2005; 94 794-809.

Supplementary Information accompanies the paper on Hypertension Research website (http://www.nature.com/hr) 